\title{
IMPACTO DE LABRANZA E INOCULACIÓN MICORRÍZICA ARBUSCULAR SOBRE LA PUDRICIÓN CARBONOSA Y RENDIMIENTO DE MAÍZ EN CONDICIONES SEMIÁRIDAS
}

\author{
IMPACT OF TILLAGE AND ARBUSCULAR MYCORRHIZA INOCULATION ON CHARCOAL ROT \\ AND YIELD OF MAIZE UNDER SEMIARID CONDITIONS
}

\author{
Arturo Díaz Franco ${ }^{1 *}$, Jaime R. Salinas García ${ }^{1}$, Idalia Garza Cano y Netzahualcóyotl Mayek Pérez ${ }^{2}$
}

\begin{abstract}
${ }^{1}$ Campo Experimental Río Bravo, Instituto Nacional de Investigaciones Forestales, Agrícolas y Pecuarias. Carr. Matamoros-Reynosa, km 61. Apartado Postal 172. 88900, Río Bravo, Tam., México. Tel. (899) 9341045. ${ }^{2}$ Centro de Biotecnología Genómica, Instituto Politécnico Nacional. Blvd. del Maestro s/n, esquina Elías Piña, Col. Narciso Mendoza. 77810, Reynosa, Tam., México.
\end{abstract}

*Autor para correspondencia (diaz.arturo@inifap.gob.mx)

\section{RESUMEN}

La labranza de conservación promueve la sostenibilidad de los suelos agrícolas y la inoculación de hongos micorrízicos arbusculares (HMA) promueven el crecimiento y el rendimiento de los cultivos. En este trabajo se determinó el efecto individual y combinado de sistemas de labranza e inoculación de HMA sobre la incidencia y severidad de la pudrición carbonosa (Macrophomina phaseolina) y el rendimiento de grano en maíz (Zea mays L.). El estudio se realizó en condiciones de secano semiárido. En el híbrido de maíz 'Pioneer $3025 W^{\prime} \circledast$ se probaron tres factores con diferentes niveles: cuatro sistemas de labranza (barbecho o labranza convencional, subsoleobordeo, destronque-bordeo y labranza cero); dos tipos de fertilización (inoculación de la semilla con el HMA Glomus intraradices; y testigo con 60N-40P-00K); $y$ tres años de evaluación (2003 a 2005). Se midió el índice de clorofila (IC), la incidencia (IM) y severidad (SM) de M. phaseolina, la colonización micorrízica (CM) y el rendimiento de grano (RG). La labranza cero presentó la menor IM y SM de pudrición carbonosa, pero también el menor RG. Los sistemas de labranza no afectaron la $\mathrm{CM}$ del maíz. La inoculación resultó igual que la fertilización química en IC, IM, SM y RG. Los mayores valores de IC, menores IM y SM y mayor RG se observaron en 2004, año en que llovió más $(460 \mathrm{~mm})$, que en $2003(230 \mathrm{~mm})$ y 2005 (125 $\mathrm{mm})$. La labranza de conservación en maíz puede reducir los daños por pudrición carbonosa, pero con pérdidas en rendimiento, con respecto a la labranza convencional.

Palabras clave: Macrophomina phaseolina, Zea mays, colonización micorrízica, labranza de conservación.

\section{SUMMARY}

Conservation tillage promotes agricultural soil sustainability and the inoculation of arbuscular mycorrhiza fungi (AMF) enhances crop growth and yields. In this study, single and combined effects of tillage systems and inoculation of AMF on charcoal rot (Macrophomina phaseolina) incidence and severity, and grain yield in maize (Zea mays L.) were determined. The study was conducted in semiarid dryland conditions. Three factors with different levels were tested in maize hybrid 'Pioneer 3025W' ${ }^{\circledR}$ : four tillage systems (moldboard or conventional tillage, subsoil-bedding, shred-bedding and no-tillage); two fertilization levels (inoculated seeds with AMF Glomus intraradices, and fertilization rate of $60 \mathrm{~N}-40 \mathrm{P}-00 \mathrm{~K})$; and three years of evaluation (2003 to 2005). Chlorophyll leaf index (CI), incidence (IM) and severity (SM) of M. phaseolina, arbuscular mycorrhizal colonization (AMC), and grain yield (GY) were determined. No tillage showed the lowest charcoal rot (IM and SM), but also the lowest GY. Tillage systems did not affect AMC of maize. Inoculation was similar to chemical fertilization in CI, IM, SM and GY, although with increase of AMC on mycorrhization treatment. The highest values CI, lesser IM and SM, and highest GY were found in 2004 due to the highest rain fall $(460 \mathrm{~mm})$ compared to $2003(230 \mathrm{~mm})$ and $2005(125 \mathrm{~mm})$. Results indicate that conservation tillage is a strategy to reduce charcoal in maize crop, although associated with grain yield losses, respect to conventional tillage.

Index words: Macrophomina phaseolina, Zea mays, mycorrhizal colonization, conservation tillage.

\section{INTRODUCCIÓN}

El deterioro de agroecosistemas en regiones semiáridas ha provocado problemas de erosión y desertificación. La pérdida de la cobertura vegetal disminuye el contenido de materia orgánica y la disponibilidad de agua y nutrimentos, principalmente nitrógeno $(\mathrm{N})$ y fósforo $(\mathrm{P})(\mathrm{Ba}-$ yer et al., 2001; Roldán et al., 2005), por lo que se ha puesto atención a la aplicación de prácticas culturales que incrementen la transformación y la retención de materia orgánica en el suelo para mantener los agroecosistemas sostenibles, como en el caso de la labranza de conservación, mediante la cual se incorporan total o parcialmente los residuos de cosecha y promueven la acumulación de la materia orgánica en el suelo. En México se practica la labranza de conservación en $3.2 \%$ de la superficie agrícola total (Salinas et al., 2002; Roldán et al., 2006) e incluye prácticas como labranza cero y labranza reducida, y ésta última incluye el destronque-bordeo y el subsuelobordeo (Roldán et al., 2005; Salinas et al., 2005). El uso 
de los sistemas de labranza de conservación tiene efectos benéficos, como reducción de la erosión, de maleza y de fertilizantes químicos, y la restauración de la fertilidad del suelo, debido fundamentalmente a los residuos de cosecha (Salinas et al., 2002; Tiscareño et al., 1999).

La simbiosis de plantas con hongos micorrízicos arbusculares (HMA) ha demostrado ser fundamental para la sustentabilidad y sostenibilidad de los ecosistemas. Los HMA interactúan con suelo, planta, patógenos y otros microorganismos del suelo, y así mejoran la nutrición y sanidad de la planta (Jeffries et al., 2003). Esa respuesta obedece a factores originados de la simbiosis, como el que las hifas sean capaces de explorar mayor volumen de suelo y llegar a sitios donde la raíz no puede penetrar; disminuir los efectos de condiciones abióticas adversas para la planta; estimular el crecimiento vegetal debido a la producción de fitohormonas; facilitar la absorción de nutrimentos, como $\mathrm{P}$ y elementos menores; producir glomalina que adhiere y aglutina partículas del suelo; e inducir acción protectora contra algunos patógenos del suelo (González et al., 2004; Ferrera-Cerrato y Alarcón, 2008).

En plantas micorrizadas de maíz (Zea mays L.) se han reportado incrementos en biomasa, proteína soluble, contenido foliar de $\mathrm{P}, \mathrm{N}, \mathrm{K}, \mathrm{Ca}, \mathrm{Mg}$ y $\mathrm{Zn}$, y de rendimiento, comparadas con plantas no micorrizadas (Arihara y Karasawa, 1999; Khalil et al., 1994). Los beneficios que aportan los HMA a los cultivos los hacen competitivos con los fertilizados en forma inorgánica (Díaz et al., 2005; Ferrera-Cerrato y Alarcón, 2008; Irízar et al., 2003). Según McGonigle et al. (1999) y Miller y Jastrow (1992), cuando la labranza se intensifica se originan disturbios en el suelo que afectan los propágulos de los HMA, se reduce la micorrización, y en maíz hay menor absorción de P. En frijol (Phaseolus vulgaris L.) cultivado en diferentes sistemas de labranza, Salinas et al. (2005) reportaron que los niveles de materia orgánica, N, P y K en tres profundidades de suelo, fueron semejantes cuando se comparó la fertilización 40N-20P-00K con la inoculación de HMA.

Macrophomina phaseolina (Tassi) Goid. es un hongo del suelo que causa la enfermedad conocida como pudrición carbonosa y ataca a casi 100 familias de plantas, particularmente en ambientes cálidos y secos (Kending et al., 2000; Claflin y Giorda, 2002). Se manifiesta con la presencia de microesclerocios, comúnmente al final del ciclo de los cultivos cuando las temperaturas del suelo son superiores a $32{ }^{\circ} \mathrm{C}$ y existe estrés de humedad (Almeida $e t$ al., 2003; Claflin y Giorda, 2002). Sus síntomas en maíz son secado prematuro del tallo, seguido de presencia de microesclerocios negros en el exterior e interior de la base del tallo, y pudrición completa que le da un aspecto deshilachado a las fibras vasculares (Kucharek y Raid, 2000; Girón, 1993; CIMMYT, 2004).

En México la pudrición carbonosa en maíz está presente en los Estados de Tamaulipas, Guerrero y Veracruz, y en Tamaulipas su incidencia ha alcanzado $60 \%$ en parcelas comerciales. Conforme es más temprana la infección, mayores son las pérdidas de producción (Girón, 1992; Rodríguez y Díaz, 1989). No obstante que en infecciones tardías el patógeno no impacta directamente al rendimiento del maíz, las plantas pueden acamarse (en particular cuando hay fuertes vientos), con las consecuentes pérdidas en la cosecha donde la práctica está mecanizada (Girón, 1993; Kucharek y Raid, 2000; Doubrava y Blake, 2004). Según Montes y Díaz (2006), además de la búsqueda de genotipos de maíz tolerantes a pudrición carbonosa, falta información acerca de otras opciones para el manejo de la enfermedad, como la irrigación y la labranza de conservación (Díaz y Cortinas, 1988; Almeida et al., 2003; Claflin y Giorda, 2002). También se desconoce la influencia de los HMA sobre M. phaseolina.

El objetivo del presente estudio fue determinar el efecto de sistemas de labranza y la inoculación de un HMA, sobre el rendimiento de grano y la intensidad de pudrición carbonosa en maíz en condiciones semiáridas.

\section{MATERIALES Y MÉTODOS}

\section{Descripción del sitio experimental}

Esta investigación se desarrolló en condiciones de temporal o secano en Río Bravo, Tamaulipas, México ( $\left.25^{\circ} 57^{\prime} \mathrm{LN}, 98^{\circ} 01^{\prime} \mathrm{L}\right)$, cuyo clima es semiárido, con temperatura anual de $23{ }^{\circ} \mathrm{C}$ y precipitación anual de 635 $\mathrm{mm}$. El suelo es un vertisol (FAO, 1988) desarrollado de sedimentos aluviales, con textura arcillosa ( $28 \%$ arena, $31 \%$ limo y $41 \%$ arcilla), con $1.2 \%$ de materia orgánica y pH de 7.8 (1:2 suelo/agua). Durante el periodo 2002 al 2005, el manejo agronómico fue cultivo-descanso, que significa un cultivo de maíz por año (febrero junio) seguido de un periodo de barbecho (agosto a enero), para retener humedad en el suelo. Las siembras fueron mecanizadas, con humedad residual, y se hicieron a principios de febrero, con una densidad aproximada de 45000 plantas/ha, con el híbrido 'Pioneer $3025 \mathrm{~W}$ ' ${ }^{\circledR}$.

\section{Diseño y manejo experimental}

El experimento de campo se inició en 2002 en un diseño factorial con tres factores. El primer factor (A) en parcelas de $52 \mathrm{~m}$ de longitud por $10 \mathrm{~m}$ de ancho (12 surcos) y tres repeticiones, correspondieron a cuatro tratamientos de sistemas de labranza: a) Barbecho o labranza 
convencional (rastra después de cosecha, seguido de barbecho con arado de rejas, rastreo y bordeo); b) Subsuelobordeo (desvare de residuos después de cosecha, seguido de subsoleo y bordeo en la misma operación); c) Destronque-bordeo (desvare después de cosecha, seguido de contra bordeo de los surcos antiguos); y d) Labranza cero [desvare después de cosecha y aplicación de glifosato (1.5 $\left.\mathrm{L} \mathrm{ha}^{-1}\right)$ y 2-4 D amina $\left(1.5 \mathrm{~L} \mathrm{ha}^{-1}\right)$ para controlar maleza de hoja ancha y angosta]. La preparación del suelo en los tratamientos de labranza se hizo durante los meses de julio y agosto, antes de las lluvias. El segundo factor (B) en parcelas de 5 x $52 \mathrm{~m}$, fue la inoculación micorrízica: 1) Inoculación de semilla con el HMA Glomus intraradices Schenck \& Smith, con $1 \mathrm{~kg}$ del inoculante micorrízico aplicado en $18 \mathrm{~kg}$ de la semilla de maíz para una hectárea, mezcla hecha con $60 \mathrm{~mL}$ de carboxi-metil-celulosa como adherente y aproximadamente $800 \mathrm{~mL}$ de agua (Díaz et $a l ., 2005)$; y 2) Testigo con fertilización inorgánica en presiembra, $60 \mathrm{~N}-20 \mathrm{P}-00 \mathrm{~K}$. El inoculante a base de $G$. intraradices es una cepa regional, propagada en pasto $\mathrm{Su}-$ dán (Sorghum vulgare sudanensis Hitch.) con una mezcla de raíces (con $\geq 75 \%$ de colonización micorrízica) y suelo con no menos de 400 esporas/g, que fue triturado y molido (comercializado por el Patronato para la Investigación, Fomento y Sanidad Vegetal, en Matamoros, Tam.). El tercer factor (C) fueron los años: de 2003 a 2005.

\section{Variables evaluadas}

En los surcos centrales de cada parcela de $5 \times 52 \mathrm{~m}$ se marcaron aleatoriamente tres subparcelas de dos surcos de $10 \mathrm{~m}$. Durante la floración se estimó el contenido de clorofila in situ mediante lecturas tomadas de la parte central (sentido longitudinal y transversal) de 30 hojas de mazorca, con un medidor portátil Minolta SPAD-502. Marquard y Tipton (1987) evaluaron ese medidor en 12 especies de plantas y sus lecturas correlacionaron significativamente $\left(r^{2}=0.83\right.$ a 0.97 entre especies) con la clorofila extraíble. En madurez fisiológica y dentro de cada subparcela se extrajeron al azar 10 plantas con todo y raíz, con una pala, en las que se hizo un corte longitudinal de los tallos para medir la incidencia y severidad de la pudrición carbonosa; la incidencia fue referida con base en el porcentaje de plantas enfermas y la severidad al número de entrenudos infectados por $M$. phaseolina (Rodríguez y Díaz, 1989). Las raíces de las plantas se lavaron para eliminar el suelo, se cortaron en fragmentos de $1 \mathrm{~cm}$ y se tomaron submuestras de $1 \mathrm{~g}$ para determinar el porcentaje de colonización micorrízica, mediante la técnica de clareo con $\mathrm{KOH} 10 \%$ y tinción con azul tripano $0.05 \%$ (Phillips y Hayman, 1970). El rendimiento de grano $\left(\mathrm{kg} \mathrm{ha}^{-1}\right)$ se cuantificó al cosechar y trillar las mazorcas dentro de las subparcelas; la humedad del grano de maíz se ajustó a $14 \%$.

\section{Análisis estadístico}

La colonización micorrízica se cuantificó en dos (2004 y 2005) de los tres años que comprendió el estudio. Para estabilizar las varianzas, los datos del porcentaje de pudrición carbonosa (incidencia) y el número de entrenudos infectados (severidad) se transformaron mediante el cálculo de la raíz cuadrada, previo al análisis. Los efectos de los tratamientos sobre las variables se determinaron por análisis de varianza, y para la comparación de promedios entre tratamientos se utilizó la prueba de Tukey $(\alpha \leq$ $0.05)$. También se efectuaron análisis de correlación simple entre algunas variables. Los análisis estadísticos se hicieron con el programa Statgraphics Plus (Manugistics, 1997).

\section{RESULTADOS Y DISCUSIÓN}

El análisis estadístico mostró efectos significativos de los factores labranza (A) y años (C) para las variables clorofila (unidades SPAD-502), incidencia de pudrición carbonosa, número de entrenudos infectados y rendimiento de grano, mientras que el factor inoculación micorrízica (B) sólo afectó el nivel de colonización de los tejidos radicales. No hubo efecto de interacción entre los factores principales.

\section{Sistema de labranza}

La menor incidencia y severidad de $M$. phaseolina $(\mathrm{P}$ $\leq 0.05)$ se observó en la labranza cero con $5.5(30.2 \%)$ y 1.0, respectivamente. En los tipos de labranza el promedio de incidencia de la enfermedad fue $8.6(73.5 \%)$ (Cuadro 1), semejante a lo observado en parcelas comerciales y experimentales de maíz en la región (Girón, 1993; Rodríguez y Díaz, 1989). Este efecto benéfico también fue constatado por Claflin y Giorda (2002), quienes reportaron que la pudrición carbonosa en sorgo [Sorghum bicolor (L.) Moench] se redujo al mínimo (11\%) con la labranza cero, comparada con labranza mínima y convencional que registraron 23 y $39 \%$, respectivamente. Similarmente, en soya [Glycine max (L.) Merril], la labranza cero abatió la incidencia y severidad de $M$. phaseolina en 20 y $80 \%$, respectivamente, en relación con labranza convencional (Almeida et al., 2003). Es posible que las condiciones edafo-climáticas sean desfavorables para el patógeno en la labranza cero, ya que la mayor actividad microbiana en este tipo de labranza podría generar mayor antagonismo (Roldán et al., 2005; Salinas et al., 2002; Sturz et al., 1997); además, se conserva mejor la humedad, y se estabilizan las fluctuaciones de este factor en suelo (Almeida et al., 2003). 
Por el contrario, los mayores rendimientos de grano $(\mathrm{P} \leq 0.05)$ se registraron con barbecho, subsoleo-bordeo y destronque-bordeo, sistemas que fueron semejantes y cuyo promedio fue $4050 \mathrm{~kg} \mathrm{ha}^{-1}$, comparado con labranza cero (3226 kg ha-1) (Cuadro 1). De igual manera, Salinas (2004) concluyó que los sistemas de barbecho, subsoleobordeo y destronque-bordeo superó estadísticamente el rendimiento de grano de sorgo de temporal, al de labranza cero, con mayor rentabilidad (relación beneficio-costo) en los sistemas de subsuelo-bordeo y destronque-bordeo. Este autor destacó la importancia de los sistemas de labranza pues al romper las capas compactas del suelo antes de las lluvias y aumentar la infiltración de agua en el perfil del suelo, se favorece el desarrollo de los cultivos de secano.

Los resultados indican que no hubo un efecto directo de la pudrición carbonosa en el rendimiento de grano, en ningún sistema de labranza aún cuando la labranza cero redujo en más de $50 \%$ la incidencia de la enfermedad (Cuadro 1). Sin embargo, aunque en el presente estudio el acame no fue problema, es importante considerar el riesgo que representa la enfermedad, particularmente con la incidencia de fuertes vientos y pérdidas en la cosecha cuando ésta es mecanizada (Girón, 1993; Kucharek y Raid, 2000; Doubrava y Blake, 2004).

Los sistemas de labranza no influyeron en la colonización micorrízica radical (Cuadro 1), contrario a lo observado por otros autores en maíz y soya, en los que la mayor colonización ocurrió en labranza cero (Gálvez et al., 2001; McGonigle et al., 1999). Pero en trigo (Triticum aestivum L.) la colonización micorrízica fue similar en diferentes sistemas de labranza, incluida la labranza cero (Mozafar et al., 2000). Al parecer, la rotación de cultivos en los sistemas de labranza podría tener influencia en la colonización de micorriza arbuscular (Arihara y Karasawa, 1999; Karasawa et al., 2001). Según Roldán et al. (2006), es importante entender la dinámica de los HMA en las estrategias de su manejo, como la labranza, lo cual es poco conocido en los ecosistemas agrícolas subtropicales.

\section{Inoculación micorrízica}

La inoculación efectuada de la semilla de maíz con $G$. intraradices resultó igual que el testigo $(60 \mathrm{~N}-20 \mathrm{P}-00 \mathrm{~K})$ en cuanto al contenido de clorofila, incidencia de pudrición carbonosa, entrenudos infectados y rendimiento de grano, a pesar de que hubo mayor colonización micorrízica radical $(\mathrm{P} \leq 0.05)$ en el tratamiento inoculado (Cuadro 2). En maíz esta misma cepa del HMA ha promovido significativamente mayor producción de forraje fresco, de elote y de grano, comparado con el testigo sin fertilizante químico (Aguirre, 2006; Díaz et al., 2005; Loredo et al., 2007). Las ventajas que tiene el HMA en el contexto de sostenibilidad agrícola, se deben al bajo costo del insumo (valor comercial de los fertilizantes $\$ 850.00 \mathrm{ha}^{-1} \mathrm{vs}$. $\$ 30.00$ ha $^{-1}$ del HMA), y a que no impacta la contaminación de suelo y agua como lo hace la fertilización inorgánica (Aguirre, 2006; Olalde y Serratos, 2008). En varios cultivos se ha reportado que la inoculación micorrízica puede competir o superar los rendimientos obtenidos de la fertilización química (Sánchez, 2002; Díaz et al., 2008; Aguirre, 2006; Irízar et al., 2003). Díaz et al. (2007) compararon la rentabilidad de la producción de sorgo para grano con la inoculación de $G$. intraradices y la fertilización química (44N-37P-00K) y obtuvieron utilidades netas de $\$ 783.20 \mathrm{ha}^{-1}$ y $-\$ 465.50 \mathrm{ha}^{-1}$, respectivamente.

Cuadro 1. Valores de clorofila, incidencia y severidad de pudrición carbonosa (M. phaseolina), colonización micorrízica y rendimiento de grano de maíz en cuatro sistemas de labranza.

\begin{tabular}{lccccc}
\hline Labranza & Clorofila & Pudrición carbonosa $(\%)^{\zeta \zeta}$ & $\begin{array}{c}\text { Entrenudos infec- } \\
\text { tados (Núm. })^{\zeta \zeta}\end{array}$ & $\begin{array}{c}\text { Colonización micorrízica } \\
(\%)\end{array}$ & $\begin{array}{c}\text { Rendimiento } \\
\left(\mathrm{kg} \mathrm{ha}^{-1}\right)\end{array}$ \\
\hline Barbecho & 44.6 & $8.31 \mathrm{a}^{\zeta \zeta \zeta}$ & $1.54 \mathrm{a}$ & 38.1 & 37.8 \\
Subsoleo-bordeo & 43.9 & $9.03 \mathrm{a}$ & $1.61 \mathrm{a}$ & $4150 \mathrm{a}$ & \\
Destronque-bordeo & 42.8 & $8.35 \mathrm{a}$ & $1.51 \mathrm{a}$ & $4043 \mathrm{a}$ & $3957 \mathrm{a}$ \\
Labranza cero & 41.3 & $5.49 \mathrm{~b}$ & $1.00 \mathrm{~b}$ & 44.4 & $3226 \mathrm{~b}$ \\
Significancia & $\mathrm{ns}$ & $*$ & $* *$ & $\mathrm{~ns}$ & $*$ \\
\hline
\end{tabular}

${ }^{\zeta}$ Lecturas en unidades SPAD-502.

${ }^{\zeta \zeta}$ Valores transformados mediante raíz cuadrada.

${ }^{\zeta \zeta}$ Valores con la misma letra son semejantes entre sí (Tukey, 0.05).

$n s, *, * *$ No significativo y significativo a nivel de $\mathrm{P} \leq 0.05$ y 0.01 , respectivamente. 
Aunque en otros estudios se ha informado de la acción protectora de la inoculación de HMA contra patógenos del suelo (Dehne, 1982; Gardezi et al., 1999, 2001), en este estudio la incidencia y la severidad de $M$. phaseolina en maíz no se redujeron por la inoculación (Cuadro 2). La colonización micorrízica en maíz tampoco mostró diferencias significativas entre los años de evaluación, que en promedio de dos años fue $40.6 \%$. A pesar de que el año 2004 registró la mayor lluvia acumulada en el ciclo del cultivo y superó en $335 \mathrm{~mm}$ a la de 2005 , el porcentaje de colonización micorrízica permaneció constante. Algunos estudios en campo con gradientes de humedad en el suelo muestran resultados contradictorios sobre el nivel de colonización micorrízica (Al-Karaki et al., 2004; Sylvia et $a l .$, 1993). El efecto que ejerce la humedad del suelo sobre la colonización micorrízica no se ha esclarecido, por lo que Augé (2004) indica que en la simbiosis de HMAplanta, las relaciones del agua y las propiedades de retención de humedad en el suelo, son fenómenos poco conocidos.

\section{Años de evaluación}

Entre los años hubo variaciones significativas $(\mathrm{P} \leq$ 0.01 ), ya que los mayores valores de clorofila, la menor incidencia y severidad de $M$. phaseolina y el mayor rendimiento de grano se obtuvieron en 2004 (Cuadro 3). Un elemento importante en agricultura de secano en ambiente semiárido que se asocia a la respuesta de la planta es la cantidad de lluvia. Al respecto, en 2004 fue el mayor registro con $460 \mathrm{~mm}$ de agua acumulada durante el ciclo biológico del cultivo, mientras que en 2003 y 2005 las lluvias fueron de 230 y $125 \mathrm{~mm}$, respectivamente. En cambio, la incidencia y la severidad de $M$. phaseolina se incrementaron conforme disminuyeron las precipitaciones, ya que al patógeno le favorecen condiciones con limitaciones de humedad edáfica (Díaz y Cortinas, 1988; Cardona, 2006; Claflin y Giorda, 2002). Almeida et al. (2003) también reportaron que la severidad de M. phaseolina en soya en Brasil se incrementó significativamente en los ciclos agrícolas con menor precipitación (474 vs. 650 $\mathrm{mm})$. Similarmente Cardona (2006) reportó que las poblaciones de microesclerocios de $M$. phaseolina en un suelo naturalmente infestado se incrementaron conforme aumentó la temperatura y disminuyó la humedad en el suelo.

Respecto a las asociaciones entre las variables, el contenido de clorofila foliar en la etapa de floración correlacionó con el rendimiento de grano $\left(\mathrm{r}=0.93^{* *}\right)$, lo que sugiere que el contenido de clorofila foliar es un indicador del estatus fisiológico y sanitario de la planta, como Piekielek y Fox (1992) y Villar y Ortega (2003) encontraron en maíz. Igualmente, el porcentaje de pudrición carbonosa (incidencia) y el número de entrenudos infectados (severidad) por $M$. phaseolina estuvieron correlacionados ( $\mathrm{r}=$ $0.94 * *)$, lo cual sugiere que la enfermedad podría medirse sólo con la incidencia. Rodríguez y Díaz (1989) obtuvieron una correlación positiva $\left(\mathrm{r}=0.65^{*}\right)$ entre la incidencia de pudrición carbonosa y el número de entrenudos infectados en 628 progenies de maíz.

Cuadro 2. Valores de clorofila, incidencia y severidad de M. phaseolina, colonización micorrízica y rendimiento de grano de maíz relacionados con la inoculación de $G$. intraradices.

\begin{tabular}{lccccc}
\hline Tratamiento & Clorofila $^{\zeta}$ & $\begin{array}{c}\text { Pudrición carbonosa } \\
(\%)^{\zeta \zeta}\end{array}$ & $\begin{array}{c}\text { Entrenudos infectados } \\
(\text { Núm. })^{\zeta \zeta}\end{array}$ & $\begin{array}{c}\text { Colonización micorrízica } \\
(\%)^{\zeta \zeta \zeta}\end{array}$ & $\begin{array}{c}\text { Rendimiento } \\
\left(\mathrm{kg} \mathrm{ha}^{-1}\right)\end{array}$ \\
\hline $\begin{array}{l}\text { G. } \text { intraradices } \\
\text { Testigo }\end{array}$ & 43.1 & 7.69 & 1.41 & $46.3 \mathrm{a}$ & 3696 \\
$(60 \mathrm{~N}-20 \mathrm{P}-00 \mathrm{~K})$ & & 7.79 & 1.48 & $36.1 \mathrm{~b}$ \\
Significancia & 43.6 & $\mathrm{~ns}$ & $\mathrm{~ns}$ & $*$ & 3973 \\
\hline
\end{tabular}

${ }^{\zeta}$ Lecturas en unidades SPAD-502.

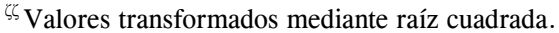

$\zeta \zeta \zeta^{\zeta \zeta}$ Valores con la misma letra son semejantes entre sí (Tukey, 0.05).

$n s, *$ No significativo y significativo a nivel de $\mathrm{P} \leq 0.05$.

Cuadro 3. Valores de clorofila, incidencia y severidad de pudrición carbonosa, y rendimiento de grano de maíz en los tres años.

\begin{tabular}{lccccc}
\hline \multicolumn{1}{c}{ Años } & Clorofila $^{\zeta}$ & $\begin{array}{c}\text { Pudrición carbonosa } \\
(\%)^{\zeta \zeta}\end{array}$ & $\begin{array}{c}\text { Entrenudos infectados } \\
(\text { Núm. })^{\zeta \zeta}\end{array}$ & $\begin{array}{c}\text { Rendimiento } \\
\left(\mathrm{kg} \mathrm{ha}^{-1}\right)\end{array}$ & $\begin{array}{c}\text { Precipitación } \\
\left(\mathrm{mm}^{2}\right)\end{array}$ \\
\hline 2003 & $43.3 \mathrm{~b}^{\zeta \zeta \zeta}$ & $8.00 \mathrm{a}$ & $1.44 \mathrm{~b}$ & $3530 \mathrm{~b}$ & 230 \\
2004 & $47.1 \mathrm{a}$ & $6.02 \mathrm{~b}$ & $1.14 \mathrm{c}$ & $5700 \mathrm{a}$ \\
2005 & $40.0 \mathrm{c}$ & $9.24 \mathrm{a}$ & $1.78 \mathrm{a}$ & $2303 \mathrm{c}$ \\
Significancia & $* *$ & $* *$ & $* *$ & 460 \\
\end{tabular}

${ }^{\zeta}$ Lecturas en unidades SPAD-502.

${ }^{\zeta \zeta}$ Valores transformados mediante raíz cuadrada.

$5 \zeta^{\zeta}$ Valores con la misma letra son semejantes entre sí (Tukey, 0.05).

** Significativo a nivel de $\mathrm{P} \leq 0.01$. 


\section{CONCLUSIONES}

La labranza cero mostró la menor incidencia y severidad de $M$. phaseolina pero también presentó el menor rendimiento de grano de maíz. La pudrición carbonosa, el índice de clorofila y el rendimiento de grano no presentaron diferencias significativas entre la inoculación micorrízica y el testigo con fertilización química, aunque tal inoculación produjo mayor colonización micorrízica. Los mayores valores del contenido de clorofila y rendimiento de grano y los menores de incidencia y severidad de $M$. phaseolina se observaron en 2004, año en que llovió más que en 2003 y 2005. Los resultados de tres años indicaron que la labranza de conservación en maíz del norte de Tamaulipas, sirve para reducir los daños por pudrición carbonosa en condiciones de secano, pero reduce en $20 \%$ el rendimiento de grano.

\section{AGRADECIMIENTOS}

Al apoyo de la Fundación Produce Tamaulipas, A. C., del Patronato para la Investigación, Fomento y Sanidad Vegetal del norte de Tamaulipas, y del Instituto Nacional de Investigaciones Forestales, Agrícolas y Pecuarias. También a Rosalío Navarro Cervantes y Juan Olvera Martínez, por su colaboración en los trabajos de campo.

\section{BIBLIOGRAFÍA}

Aguirre J L (2006) Biofertilizantes Microbianos: Experiencias Agronómicas del Programa Nacional del INIFAP en México. Campo Experimental Rosario Izapa, INIFAP. Libro Técnico No. 2. México. 206 p.

Al-Karaki G, B McMichael, J Zak (2004) Field response of wheat to arbuscular mycorrhizal fungi and drought stress. Mycorrhiza 14:263-269.

Almeida A M, L Amorim, A B Filho, E Torres, J R Farias, L C Benato, M C Pinto, N Valentim (2003) Progress of soybean charcoal rot under tillage and no-tillage system in Brazil. Fitopat. Brasileira 28:131-135.

Arihara J, T Karasawa (1999) Effect of previous crops on arbuscular mycorrhizal formation and growth of succeeding maize. Soil Sci. Plant Nutr. 46:43-51.

Augé R M (2004) Arbuscular mycorrhizae and soil/plant water relations. Can. J. Soil Sci. 84:373-381

Bayer C, L Marín-Nieto, J Mielniczuk, C N Pillon, L Sangoid (2001) Changes in soil organic matter fractions under subtropical notill cropping systems. Soil Sci. Soc. Am. J. 65:1473-1478.

Cardona R (2006) Distribución vertical de esclerocios de Macrophomina phaseolina en un suelo infestado naturalmente en el estado Portuguesa. Rev. Fac. Agron. 23:284-291.

CIMMYT, Centro Internacional de Mejoramiento de Maíz y Trigo (2004) Maize Diseases: A Guide for Field Identification. 4th ed. CIMMYT, México, D. F. 124 p.

Claflin L E, L M Giorda (2002) Stalk rots of sorghum. In: Sorghum and Millets Diseases. J F Leslie (ed). Iowa State Press. pp:181-190.

Dehne H W (1982) Interactions between vesicular-arbuscular mycorrhizal fungi and plant pathogens. Phytopathology 72:1115-1119.
Díaz F A, M Alvarado C, M Cantú A, I Garza C (2005) Fertilización biológica y producción de maíz en la región semiárida del norte de Tamaulipas, México. Agric. Téc. Méx. 31:153-163.

Díaz F A, H Cortinas E (1988) Effect of irrigation regimes on susceptibility of bean to Macrophomina phaseolina. J. Rio Grande Valley Hort. Soc. 41:47-50.

Díaz F A, I Garza C, V Pecina Q, N Montes G (2008) Respuesta del sorgo a micorriza arbuscular y Azospirillum en estrés hídrico. Rev. Fitotec. Mex. 31: 35-42.

Díaz M R, A Díaz F, I Garza C, A Ramírez L (2007) Brassinoesteroides e inoculación con Glomus intraradices en el crecimiento y la producción de sorgo en campo. Terra Latinoam. 25:77-83.

Doubrava N, J H Blake (2004) Sweet Corn Diseases. Clemson Extension. Clemson University. Publ. HGIC-2204. 2 p.

Doupnik B, MG Boosalis, G Wicks, D Smika (1975) Ecofallow reduces stalk rot in grain sorghum. Phytopathology 65:10211022.

FAO, Food Agriculture Organitation (1988) Soil Map of the World. Revised Legend. FAO, United Nations Final Draft.

Ferrera-Cerrato R, A Alarcón (2008) Biotecnología de los hongos micorrízicos arbusculares. In: Biofertilización como Tecnología Sostenible. A Díaz F, N Mayek P (eds). Plaza y Valdés/CONACYT. pp:25-38.

Gálvez L, D D Douds, L E Drinkwater, P Wagoner (2001) Effect of tillage and farming system upon VAM fungus populations and mycorrhiza and nutrient uptake of maize. Plant Soil 228:299308.

Gardezi A K, V Cetina A, R Ferrera-Cerrato, J Velásquez M, C Pérez M, M Larqué $\mathbf{S}$ (2001) Hongos micorrízicos arbusculares como componente de control biológico de la pudrición causada por Fusarium sp. en gladiola. Terra 19:259-264.

Gardezi A K, R García E, R Ferrera-Cerrato, M Larqué S (1999) Effect of arbuscular mycorrhizae on tomato (Lycoporsicon esculentum Mill.) in naturally infested soil with Fusarium oxysporum f. sp. radicis-lycopersici. Rev. Mex. Fitopatol. 17:23-28.

Girón C R (1992) Evaluación de la pudrición negra del tallo en materiales comerciales y experimentales de maíz. In: Segunda Reunión Científica, Forestal y Agropecuaria de Tamaulipas. INIFAP, SARH. México. pp:67-68.

Girón C R (1993) Maíz. In: Enfermedades Infecciosas de los Cultivos. A Díaz F (ed). Trillas. México. pp:19-34.

González Ch M, M Gutiérrez C, S Wright (2004) Hongos micorrízicos arbusculares en la agregación del suelo y su estabilidad. Terra Latinoam. 22:507-514.

Irízar G M, P Vargas, D Garza, C Tut, M Rojas, A Trujillo, R García, D Aguirre, J Martínez, S Alvarado, O Grageda, J Valero, J Aguirre (2003) Respuesta de cultivos agrícolas a los biofertilizantes en la región central de México. Agric. Téc. Méx. 29:213-225.

Jeffries P, S Gianinazzi, S Perotto, K Turnau, J M Baera (2003) The contribution of arbuscular mycorrhizal fungi in sustainable maintenance of plant health and soil fertility. Biol. Fert. Soils 37:1-16.

Karasawa T, Y Kasahara, M Takabe (2001) Variable response of growth and arbuscular mycorrhizal colonization of maize plants to preceding crops in various types of soils. Biol. Fert. Soils 33: 286-293

Kending R S, J C Rupe, H D Scott (2000) Effect of irrigation and soil water stress on densities of Macrophomina phaseolina in soil and roots of two soybean cultivars. Plant Dis. 84: 895-900.

Khalil S, T Loynachan, M Tabatabai (1994) Mycorrhizal dependency and nutrient-uptake by improved and unimproved corn and soybean cultivars. Agron. J. 86:949-958.

Kucharek T, R Raid (2000) Some diseases of corn in Florida. Florida Coop. Ext. Serv./Inst. of Food and Agr. Sci., University of Florida. Circular-1130. $15 \mathrm{p}$. 
Loredo O C, S Beltrán L, M Peña del Río (2007) Uso de biofertilizantes para la producción de maíz forrajero en condiciones de temporal. Campo Experimental San Luis, INIFAP. Folleto Científico No. 2. México. 60 p.

Manugistics, Inc. (1997) Statgraphics Plus. Version 3.1. Rockville, MD, USA.

Marquard R D, J L Tipton (1987) Relationship between extractable chlorophyll and an in situ method to estimate leaf greenness. HortScience 22:1327.

McGonigle T P, M H Miller, D Young (1999) Mycorrhizae, crop growth and crop phosphorus nutrition in maize-soybean rotations given various tillage treatments. Plant Soil 210:33-42.

Miller R M, J D Jastrow (1992) The role of mycorrhizal fungi in soil conservation. In: Mycorrhizae in Sustainable Agriculture. Bethlenfalvay G J, R G Linderman (eds). ASA Special Publ. No. 54. pp:29-44.

Montes G N, A Díaz F (2006) Fitopatología. In: Campo Experimental Río Bravo: 50 Años de Investigación Agropecuaria en el Norte de Tamaulipas. B Rodríguez L (ed). Campo Experimental Río Bravo, INIFAP. Libro Técnico No. 1. México. pp:192213

Mozafar A, T Anken, R Ruh, E Frossard (2000) Tillage intensity, mycorrhizal and nonmycorrhizal fungi and nutrient concentrations in maize, wheat and canola. Agron. J. 92:1117-1124.

Olalde P V, R Serratos (2008) Biofertilizantes: Micorrizas y bacterias promotoras de crecimiento. In: Biofertilización como Tecnología Sostenible. A Díaz F, N Mayek P (eds). Plaza y Valdés/CONACYT. pp:55-66.

Phillips J M, D S Hayman (1970) Improved procedures for clearing roots and staining parasitic and vesicular-arbuscular mycorrhizal fungi for rapid assessment of infection. Trans. Br. Mycol. Soc. 55:158-161.

Piekielek W P, R H Fox (1992) Use of chlorophyll meter to predict sidedress nitrogen requirements for maize. Agron. J. 84:5965.

Rodríguez C A, A Díaz F (1989) Evaluación de germoplasma de maíz a la pudrición carbonosa (Macrophomina phaseolina). Rev. Mex. Fitopatol. 7:215-217.
Roldán A, J R Salinas G, M M Alguacil, E Díaz, F Caravaca (2005) Soil enzyme activities suggest advantages of conservation tillage practices in sorghum cultivation under subtropical conditions. Geoderma 129: 178-185.

Roldán A, J R Salinas G, M M Alguacil, F Caravaca (2006) Soil sustainability indicators following conservation tillage practices under subtropical maize and bean crops. Soil Tillage Res. 93:273-282.

Salinas G J R (2004) Labranza de Conservación en Sorgo de Riego y Temporal en el Norte de Tamaulipas. Campo Experimental Río Bravo, INIFAP. Publ. Esp. No. 28. México. pp:15-17.

Salinas G J R, A Díaz F, E Garza C, I Garza C (2005) Efectos de labranza y biofertilización en propiedades del suelo que afectan a la sostenibilidad de la producción de frijol. Cien. Tecnol. Alim. 5:30-34.

Salinas G J R, J J Velázquez G, M Gallardo V, P Díaz M, F Caballero H, L M Tapia V, E Rosales R (2002) Tillage effects on microbial biomass and nutrient distribution in soils under rain-fed corn production in central-western Mexico. Soil Tillage Res. 66:143-152.

Sánchez C M (2002) Experiencias en la investigación con hongos micorrízicos arbusculares en los suelos de Ando. In: J Pérez M, J Alvarado L, R Ferrera-Cerrato (eds). Comité Mexicano de Inoculantes Agrícolas y Forestales, CP, INIFAP y SMCS. Texcoco, Edo. México. pp:15-25.

Sturz A V, M R Carter, H W Johnston (1997) A review of plant disease, pathogen interactions and microbial antagonism under conservation tillage in humid agriculture. Soil Tillage Res. 41:169-189.

Sylvia D M, L C Hamond, J M Bennett, J H Hass, S B Linda (1993) Field response of maize to a VAM fungus and water management. Agron. J. 85:193-198.

Tiscareño M, A Baez G, M Velázquez V, K N Potter, J J Stone, M Tapia V, R Claverán A (1999) Agricultural research for watershed restoration in central Mexico. J. Soil Water Conserv. 54:686-692.

Villar Z D, R Ortega B (2003) Medidor de clorofila: Bases teóricas y su aplicación para la fertilización nitrogenada en cultivos. Agron. Forest. 5:4-10. 